\title{
Osteopenia and decreased bone formation in osteonectin-deficient mice
}

\author{
A.M. Delany, ${ }^{1,2}$ M. Amling, ${ }^{3}$ M. Priemel, ${ }^{3}$ C. Howe,${ }^{4}$ R. Baron, ${ }^{5}$ and E. Canalis ${ }^{1}$ \\ ${ }^{1}$ Department of Research, Saint Francis Hospital and Medical Center, Hartford, Connecticut 06105, USA \\ ${ }^{2}$ University of Connecticut School of Medicine, Farmington, Connecticut 06030, USA \\ ${ }^{3}$ Department of Trauma Surgery, Universität Hamburg, 22529 Hamburg, Germany \\ ${ }^{4}$ Wistar Institute, Philadelphia, Pennsylvania 19104, USA \\ ${ }^{5}$ Department of Orthopedics and Cell Biology, Yale University School of Medicine, New Haven, Connecticut 06510, USA \\ Address correspondence to: A.M. Delany, Department of Research, Saint Francis Hospital and Medical Center, \\ 114 Woodland Street, Hartford, Connecticut 06105, USA. \\ Phone: (860) 714-4782; Fax: (860)714-8053; E-mail: adelany@stfranciscare.org.
}

A.M. Delany and M. Amling contributed equally to this work.

Received for publication April 8, 1999, and accepted in revised form February 18, 2000.

\begin{abstract}
Bone continuously remodels in response to mechanical and physiological stresses, allowing vertebrates to renew bone as adults. Bone remodeling consists of the cycled synthesis and resorption of collagenous and noncollagenous extracellular matrix proteins, and an imbalance in this process can lead to disease states such as osteoporosis, or more rarely, osteopetrosis. There is evidence that the extracellular matrix glycoprotein osteonectin or secreted protein acidic and rich in cysteine (BM-40) may be important in bone remodeling. Osteonectin is abundant in bone and is expressed in areas of active remodeling outside the skeleton. In vitro studies indicate that osteonectin can bind collagen and regulate angiogenesis, metalloproteinase expression, cell proliferation, and cell-matrix interactions. In some osteopenic states, such as osteogenesis imperfecta and selected animal models for bone fragility, osteonectin expression is decreased. To determine the function of osteonectin in bone, we used contact $x$-ray, histomorphometry, and Northern blot analysis to characterize the skeletal phenotype of osteonectin-null mice. We found that osteonectin-null mice have decreased bone formation and decreased osteoblast and osteoclast surface and number, leading to decreased bone remodeling with a negative bone balance and causing profound osteopenia. These data indicate that osteonectin supports bone remodeling and the maintenance of bone mass in vertebrates.
\end{abstract}

J. Clin. Invest. 105:915-923 (2000).

\section{Introduction}

Bone continuously remodels in response to mechanical and physiological stresses, and this remodeling allows vertebrates to renew bone as adults. Bone remodeling consists of the cycled resorption and synthesis of collagenous and noncollagenous extracellular matrix proteins. Bone resorption is performed by osteoclasts whereas synthesis is performed by osteoblasts, and an imbalance in this process can lead to disease states such as osteoporosis, or more rarely, osteopetrosis (1-4). There is evidence that osteonectin or secreted protein acidic and rich in cysteine (SPARC; BM-40) may be important in bone remodeling. This 43-kDa extracellular matrix glycoprotein is abundant in bone and is expressed in areas of active remodeling outside the skeleton $(5,6)$. In vitro studies indicate that osteonectin binds collagen and hydroxyapatite and can regulate cell proliferation and cell-matrix interactions $(5,6)$. In addition, osteonectin can stimulate angiogenesis and the production of matrix metalloproteinases (MMPs) including gelatinase B (MMP-9), stromelysin (MMP3 ), and collagenase-1 (MMP-1) $(7,8)$. Growth factors and other agents active in the bone compartment, such as TGF- $\beta$, fibroblast growth factor- 2 , bone morphogenetic protein-2, and glucocorticoids can regulate osteonectin expression (9-12).

Whereas high levels of osteonectin are associated with bone, the function of this glycoprotein in the skeleton has not been defined. It is of interest that in selected forms of osteopenia, such as osteogenesis imperfecta and several animal models of bone fragility, osteonectin expression is decreased (13-15). For example, osteoblasts from patients with osteogenesis imperfecta synthesize less osteonectin than agematched controls. The fro/fro mouse, which has a phenotype of bone fragility, synthesizes less osteonectin RNA and protein than control animals. Similarly, in one bovine model of osteogenesis imperfecta, BOITexas, osteonectin levels are only approximately $2 \%$ of those found in control animals. It is not known whether decreased osteonectin expression in bone fragility is a result of the abnormal extracellular matrix synthesized or if the decreased osteonectin expression contributes to the phenotype of bone fragility; however, both of these scenarios may be possible. 
To determine the role of osteonectin in bone, we characterized the skeletal phenotype of mice carrying a null mutation in the osteonectin gene. The osteonectin-null mice used in this study have a targeted disruption in exon 4 of the gene. These animals were generated as described and partially characterized (16). Homozygous mutant and control mice were maintained on a mixed genetic background of $129 \mathrm{SV} / \mathrm{C} 57 \mathrm{BL} / 6$, and tissue from homozygous mutant mice does not contain detectable amounts of osteonectin mRNA or protein (16). It was reported previously that osteonectin-null mice develop cataracts as early as 1.5 months of age, but do not display gross abnormalities in skeletal morphology or growth $(16,17)$. However, a comprehensive study of the skeleton of mutant mice was not reported. Using the sensitive techniques of contact $\mathrm{x}$-ray and histomorphometry we found that osteonectin-null mice display decreased bone remodeling with a marked negative bone balance, leading to profound osteopenia.

\section{Methods}

Animals. Mice were generated and maintained on a mixed genetic background of $129 \mathrm{SV} / \mathrm{C} 57 \mathrm{BL} / 6$ as described previously (16). All groups of mice analyzed contained both males and females. For studies of 11-week-old animals, homozygous wild-type and osteonectin-null litter mates, as well as heterozygotes, were characterized. As the skeletal phenotype of the osteonectin-null mice was apparent from these animals, analysis of the older animals, 17 and 36 weeks, were performed on the progeny of homozygous wild-type or osteonectin-null crosses. Whereas the genetic background of these animals may not have been identical, the gross phenotype of the mutant mice, osteopenia, and cataracts, was maintained. Mice were sacrificed by $\mathrm{CO}_{2}$ asphyxiation, using a protocol approved by the Saint Francis Hospital and Medical Center Animal Care and Use Committee.

Histomorphometry and radiographic analysis. After wholeanimal contact radiography (Faxitron X-ray Corporation, Wheeling, Illinois, USA), bones were dissected and fixed in buffered 3.7\% formaldehyde for 16 hours at $4^{\circ} \mathrm{C}$. After dehydration, undecalcified bones were embedded in methylmethacrylate and $5-\mu \mathrm{m}$ sections were prepared on a MicroTec rotation microtome (Techno-Med Bielfeld, Germany) as previously described (18). Sections were stained with toluidine blue, von Kossa or Goldner trichrome, and evaluated on a Zeiss microscope (Carl Zeiss, Jena, Germany). Quantitative histomorphometry was performed on toluidine blue-stained, undecalcified sections of proximal tibia and lumbar spine according to American Society for Bone and Mineral Research standards using the Osteomeasure histomorphometry system (Osteometrics, Atlanta, Georgia, USA) (19). For assessment of dynamic histomorphometric indices (bone-formation rate), mice were injected with calcein $(25 \mathrm{mg} / \mathrm{kg}) 12$ days and 2 days before sacrifice, according to a standard double-labeling protocol (20).
Biomechanical properties. A 3-point bending test was performed as described previously using a commercial high-precision instrument (Z2.5/TN $1 \mathrm{~S}$ testing machine; Zwick GmH and Co., Ulm, Germany) (21). Femurs were dissected free of soft tissue, and the ends of the bones were supported on 2 fulcrums separated by $5 \mathrm{~mm}$. A load was applied to the anterior midshaft at a constant speed of $10 \mathrm{~mm} / \mathrm{min}$ to failure. The ultimate force and the ultimate deformation were determined directly from force-deformation curves. Stiffness was assessed as the slope of the force-deformation curve.

$R N A$ analysis. Calvariae and femurs, dissected free of adherent tissue and flushed of bone marrow, were snap-frozen in liquid nitrogen. Bones from 3-4 agematched animals were pooled for RNA isolation. Bones were homogenized in buffer containing $4 \mathrm{M}$ guanidinium thiocyanate, and RNA was extracted with acid phenol and precipitated with isopropanol (22). Total RNA (10 $\mu \mathrm{g} /$ lane) was denatured and subjected to electrophoresis through formaldehyde/ agarose gels and blotted on to GeneScreen Plus as directed by the manufacturer (NEN Life Science Products Inc., Boston, Massachusetts, USA). The cDNA fragments were labeled with $\alpha-{ }^{32} \mathrm{P}$-dCTP by random priming (Amersham Pharmacia Biotech, Piscataway, New Jersey, USA). The cDNAs used were bovine osteonectin, mouse bone sialoprotein, mouse osteo-
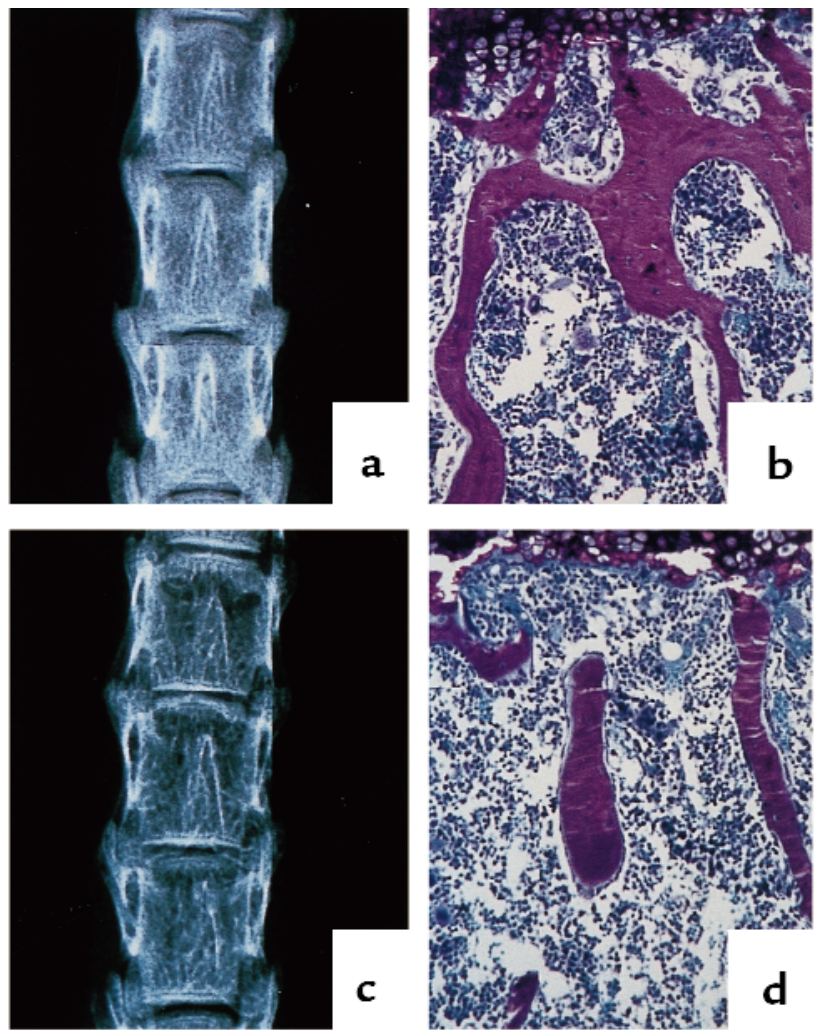

Figure 1

Radiographic and histologic analysis of vertebrae from 11-week-old control and osteonectin-null mice. Vertebrae from 11-week-old control (a, b) and osteonectin-null (c, d) mice were analyzed by x-ray (a, c) and toluidine blue staining $(\mathbf{b}, \mathbf{d})$. 

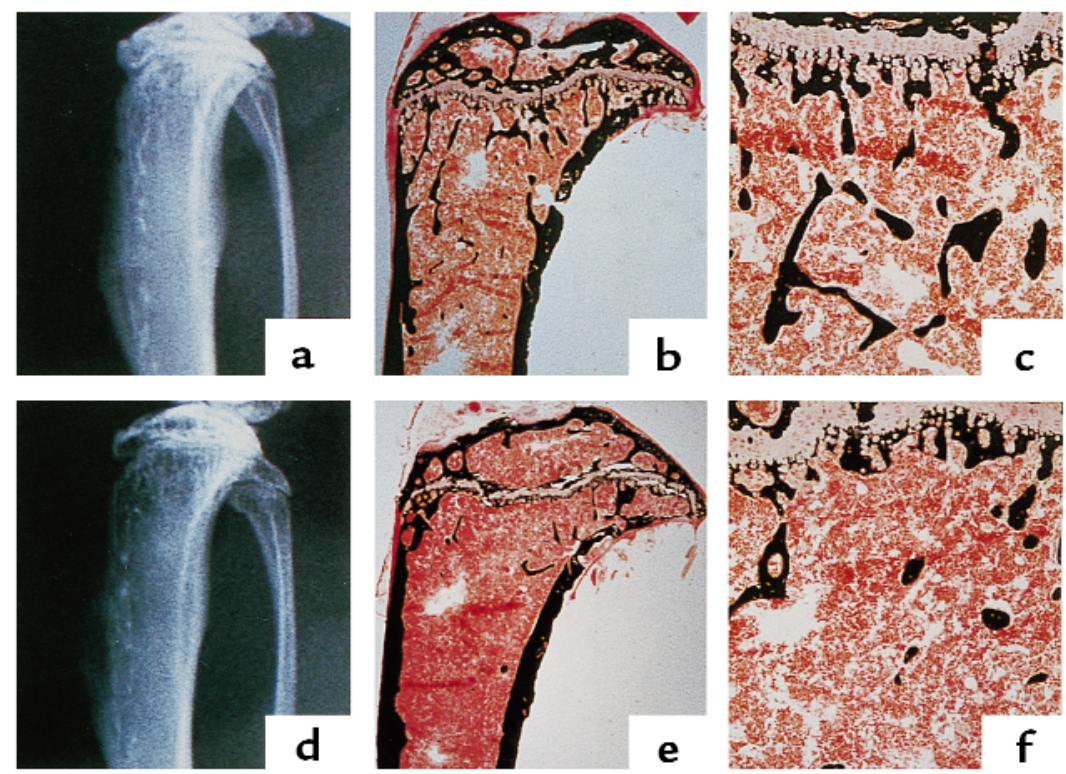

\section{Figure 2}

Radiographic and histologic analysis of proximal tibiae from 11-week-old control and osteonectin-null mice. Tibiae from 11-week-old control $(\mathbf{a}-\mathbf{c})$ and osteonectin-null $(\mathbf{d}-\mathbf{f})$ mice were analyzed by $\mathbf{x}$-ray $(\mathbf{a}, \mathbf{d})$ and von Kossa staining, which stains mineralized matrix black $(\mathbf{b}, \mathbf{c}$, e, f). Staining, viewed at a higher magnification (c, f).

pontin, rat fibronectin, rat $\alpha 1(\mathrm{I})$ collagen, rat osteocalcin, mouse gelatinase $\mathrm{B}$, human gelatinase $\mathrm{A}$, rat collagenase-3, mouse VEGF, and rat GAPDH (23-32). Hybridizations were carried out at $42^{\circ} \mathrm{C}$ in $50 \%$ formamide, $750 \mathrm{mM}$ sodium chloride, $50 \mathrm{mM}$ sodium phosphate, 5 mM EDTA, $5 \times$ Denhardt's solution, and 0.4\% SDS (Sigma Chemical Co., St. Louis, Missouri, USA). Posthybridization washes were performed at $65^{\circ} \mathrm{C}$ in $150 \mathrm{mM}$ sodium chloride, $15 \mathrm{mM}$ sodium citrate, and $0.1 \%$ SDS. Appropriate exposures of autoradiographs were analyzed by densitometry.

Biochemical assays. Blood and urine were collected from age-matched mice. To determine osteocalcin levels in the serum, a mouse osteocalcin radioimmunoassay was performed as described by Gundberg et al. (33) (all reagents from Biomedical Technologies, Stoughton, Massachusetts, USA). Total deoxypyridinoline cross-links in the urine were determined using the Pyrilinks-D ELISA (Metra Biosystems, Mountain View, California, USA) (34). Mouse urine was hydrolyzed by boiling 18 hours in $6 \mathrm{~N} \mathrm{HCl}$ and was neutralized before the assay. Urinary creatinine concentration was determined using an alkaline picrate quantitative colorimetric assay, and deoxypyridinoline cross-links are expressed relative to creatinine concentration (Creatinine Kit; Metra Biosystems, Mountain View, California, USA).

\section{Results}

Contact $\mathrm{x}$-ray and histomorphometric analysis of undecalcified bone showed that the osteonectin-null mutation severely affects trabecular bone, the type of tissue found in vertebrae and the metaphysis of long bones. Trabecular bone is responsible for much of the metabolic function of bone, and it is the region of the tissue most susceptible to loss of bone mass due to calcium deficiency, estrogen deficiency, or loss of weight bearing $(1,2)$. Although analysis of neonatal and 6-week-old animals failed to demonstrate significant differences in trabecular bone, $\mathrm{x}$-ray and histomorphometric analysis demonstrated that, compared with age-matched controls, osteonectin-null mice had decreased trabecular bone at 11 weeks of age. The vertebrae of 11-week-old osteonectin-null mice had decreased radiographic density, and trabecular bone volume (BV/TV) in mutant mice was approximately $50 \%$ lower than in control mice (Figure 1) (control $21.4 \% \pm 1.4$ vs. mutant, $11.3 \% \pm 0.3$; $n$ $\geq 4$ ). Decreased radiographic density and decreased trabecular bone were also evident in the metaphysis and epiphysis of the tibia and femur (Figure 2, and data not shown). At this age, differences in trabecular bone were more dramatic in the vertebrae than in the tibia. One copy of a functional osteonectin gene was sufficient to rescue the phenotype, because mice heterozygous for the osteonectin-null mutation had a skeletal phenotype identical to that of the homozygous control animals (data not shown).

Histomorphometric analysis of tibia showed that the difference in trabecular bone volume between the control and osteonectin-null mice became greater as the animals became older. The osteonectin-null mice had approximately $50 \%$ less trabecular bone than control mice at 17 weeks of age and approximately $70 \%$ less trabecular bone at 36 weeks of age, suggesting a cumulative effect (Figure 3a). The decrease in trabecular bone volume in the mutant mice was reflected by changes in trabecular number and spacing. At 17 

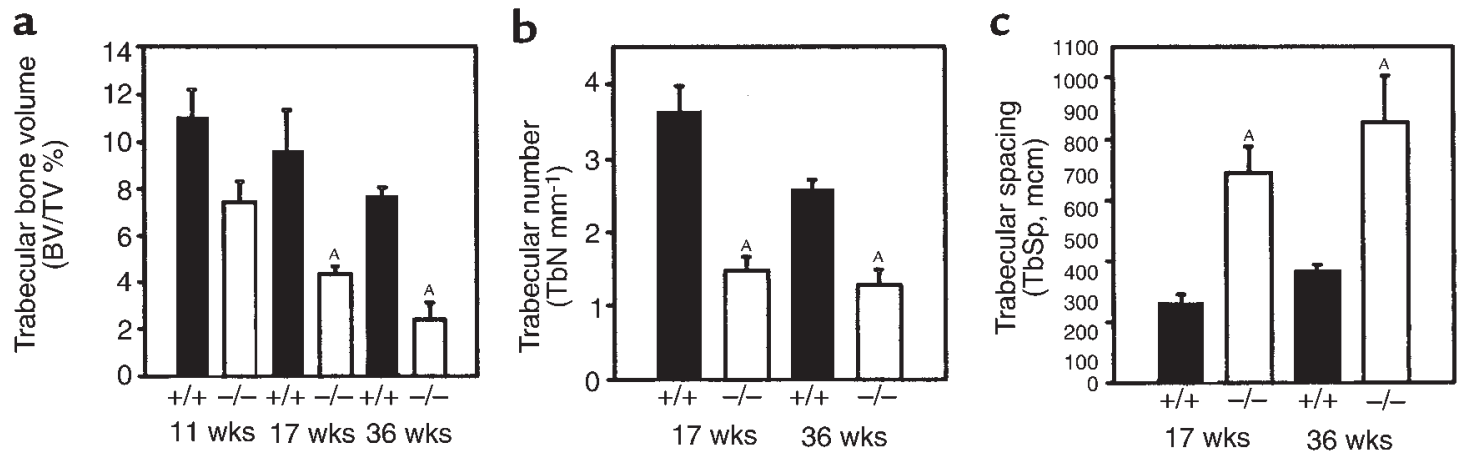

\section{Figure 3}

Histomorphometric analysis of trabecular bone volume in tibiae of control (+/+) and osteonectin-null (-/-) mice. Trabecular bone volume is expressed relative to tissue volume and represents bone mass $(\mathbf{a})$. Changes in trabecular number $(\mathbf{b})$ and spacing $(\mathbf{c})$ between control and osteonectin-null mice reflect the changes in trabecular bone volume. Bars show means $\pm \operatorname{SEM}(n \geq 4)$. ${ }^{A} P<0.01$ between control and mutant mice, as determined by 2-way ANOVA.

weeks of age, the osteonectin-null mice had approximately $60 \%$ fewer trabeculae than age-matched control animals, and trabecular spacing in the mutant animals was increased approximately 2 -fold (Figure $3, \mathrm{~b}$ and c). Similar effects on trabecular spacing and number were seen in 36-week-old mice. This loss of trabecular elements reduced the number of interconnections between the trabeculae, a phenomenon clearly visible in the bone sections (Figures 1 and 2). In humans, loss of trabecular connectivity plays a significant role in skeletal fragility (35).

Control and osteonectin-null mice did not have significant differences in cortical bone thickness at any age tested, up to 36 weeks (data not shown). However, to determine if the osteonectin-null mutation affected the strength (maximum load) or flexibility (stiffness) of the cortical bone, biomechanical properties of the femurs from control and osteonectin-null mice were assayed in a 3-point bending test. Whereas there were no significant differences in the biomechanical properties of bones from 11-week-old mice, by 17 weeks bones of the control mice gained strength, whereas those of the mutant mice did not. As expected, bones from 36-week-old control lost strength, a result of normal aging, whereas the strength of bones from mutant mice did not change (Table 1).
Histomorphometry revealed that the osteonectinnull mutation affected osteoblast and osteoclast numbers and surface. Compared to age-matched controls, osteoblast number in the osteonectin-null mice was decreased by approximately $30 \%$ at 17 weeks and by approximately $60 \%$ at 36 weeks of age, with similar changes in osteoblast surface (Figure 4, a and c). Osteonectin-null mice also had decreased osteoclast number and surface (Figure 4, b and d). Osteonectinnull mice had approximately $60 \%$ fewer osteoclasts than age-matched controls at 17 weeks of age. However, there was little difference in osteoclast number in 36-week-old animals because the number of osteoclasts in control mice had decreased, reflecting decreased remodeling in the older animals. Osteoclast surface was affected in a similar manner. To determine the effect of the osteonectin-null mutation on bone-formation rate, calcein double-labeling of mineralized matrix was used. As expected, trabecular bone-formation rate decreased in control and mutant mice as the animals aged. However, the bone-formation rate of the osteonectin-null mice was significantly less than that of control mice at each age tested. By 36 weeks of age, trabecular bone-formation rate in the mutant mice was decreased by $85 \%$ compared with the controls, further illustrating the cumulative

Table 1

Biomechanical properties of bone from control and osteonectin-null mice

\begin{tabular}{lcccc}
\hline Property & Mouse type & 11 weeks & 17 weeks & 36 weeks \\
Maximum load & Control & $14.85 \pm 0.69$ & $18.82 \pm 1.58$ & $15.55 \pm 1.79$ \\
$(\mathrm{~N})$ & Osteonectin-null & $14.86 \pm 0.50$ & $16.41 \pm 0.81$ & $12.96 \pm 1.99$ \\
Maximal displacement & Control & $0.44 \pm 0.03$ & $0.35 \pm 0.07$ & $0.32 \pm 0.08$ \\
$(\mathrm{~mm})$ & Osteonectin-null & $0.45 \pm 0.03$ & $0.49 \pm 0.07^{\mathrm{A}}$ & $0.40 \pm 0.07$ \\
Stiffness & Control & $33.19 \pm 2.38$ & $64.59 \pm 10.93$ & $47.75 \pm 12.68$ \\
$(\mathrm{~N} / \mathrm{mm})$ & Osteonectin-null & $32.03 \pm 1.77$ & $35.77 \pm 6.59^{\mathrm{A}}$ & $31.76 \pm 9.10$
\end{tabular}

A 3-point bending test was used to assess the biomechanical properties of femora from 11-, 17-, and 36-week-old control and osteonectin-null mice. Data shown are mean $\pm \mathrm{SD}(n \geq 4)$. ${ }^{\mathrm{A}} P<0.05$ between control and mutant mice, as determined by 2-way ANOVA. 

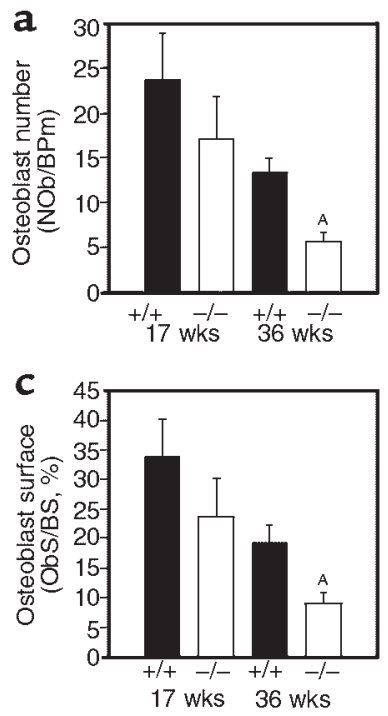
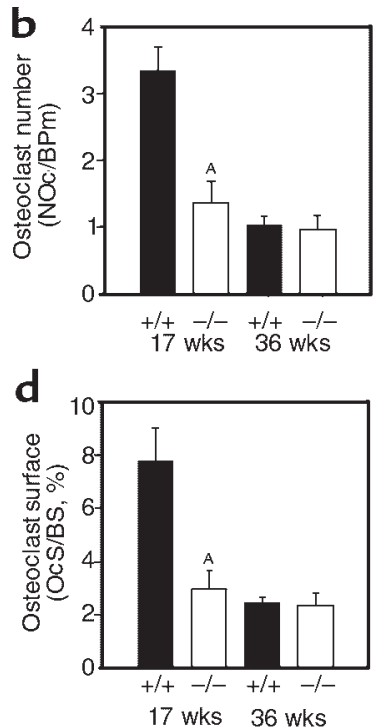

\section{Figure 4}

Histomorphometric analysis of osteoblasts and osteoclasts in tibiae of control $(+/+)$ and osteonectinnull (-/-) mice. Osteoblast or osteoclast number (a, b) and the proportion of the bone covered with osteoblasts or osteoclasts (surface) (c, d) reflect bone cell quantity. Bars show mean $\pm \operatorname{SEM}(n \geq 4)$. ${ }^{A} P<0.01$ between control and mutant mice, as determined by 2-way ANOVA. BPm, bone perimeter; BS, bone surface. nature of the defect (Figure 5). Whereas cortical boneformation rate was similarly affected, there was no change in cortical bone thickness, suggesting less bone resorption in cortical bone than in trabecular bone (data not shown).

Serum osteocalcin levels and urinary deoxypyridinoline levels are often used as biochemical markers of bone turnover, and these parameters were assayed in control and osteonectin-null mice at different ages (Table 2) (36). Serum osteocalcin is considered a marker of osteoblastic function and was determined by specific radioimmunoassay. With increasing age, serum osteocalcin levels decreased in control and mutant mice, reflecting the decrease in bone formation associated with aging. However, there were no significant differences in serum osteocalcin levels between control and mutant mice at 11 and 17 weeks of age. At 36 weeks, serum osteocalcin in osteonectin-null animals was below the limit of detection of the assay, whereas levels were low, but detectable, in control mice. These data suggest a difference in serum osteocalcin at this age, although statistical evaluation is difficult. Total urinary deoxypyridinoline levels, a marker of bone resorption, were measured by ELISA, and no statistically significant differences were observed between control and mutant animals or between the ages tested. In this instance, it is not surprising that the biochemical parameters of bone turnover did not correlate well with the decrease in trabecular bone and changes in bone cell number found in mutant mice by histomorphometry, because of the reduced sensitivity of the biochemical markers compared with histomorphometric evaluation and the limited effect of the osteonectin-null mutation on cortical bone.

Although overexpression of osteonectin in transgenic nematodes causes embryonic abnormalities and injection of antibodies against osteonectin into Xenopus embryos causes developmental defects, osteonectin-null mice have normal embryonic skeletal development $(6,16,17)$. To determine whether altered expression of other bone matrix products may have compensated for the lack of osteonectin, Northern blot analysis of RNA from femurs and calvariae of 11, 17-, and 36-week-old mice was performed (Figure 6 and data not shown). No appreciable or consistent differences in the expression of bone sialoprotein, fibronectin, osteocalcin, osteopontin, or $\alpha 1$ (I) procollagen mRNA were noted between control and mutant mice. RNA isolated from femurs and calvariae gave similar results, suggesting that osteonectinnull mutation affected bones formed by intramembranous and endochondral ossification in a similar manner (Figure 6).

Studies in nonskeletal tissues showed that osteonectin can induce expression of MMPs. Osteoblasts synthesize a number of MMPs including gelatinase A (MMP-2), gelatinase B (MMP-9), collagenase-3 (MMP13), collagenase-1 (MMP-1), and stromelysin-3 (MMP11), whereas osteoclasts express gelatinase B and MT1 MMP (23, 37-41). MMPs are important in the breakdown of extracellular matrix associated with bone remodeling and gelatinase- $\mathrm{B}$, in particular, is important for growth-plate angiogenesis (42). Northern blot analysis of RNA from 11-, 17-, and 36-week mouse calvariae and femurs showed little difference in the abundance of mRNA for collagenase-3 or gelatinase-A in bones from control and osteonectin-null mice, whereas an inconsistent decrease in gelatinase $B$ mRNA was noted at 11 weeks (Figure 6 and data not shown). These data suggest that metalloproteinase expression was not severely altered by the osteonectinnull mutation.

Osteonectin can induce angiogenesis, and neovascularization is important for normal ossification. VEGF is a potent angiogenic factor expressed by osteoblasts and hypertropic chondrocytes, therefore the expression of VEGF mRNA in bones from control and osteonectin-null mice was examined $(6,43,44)$. The VEGF 

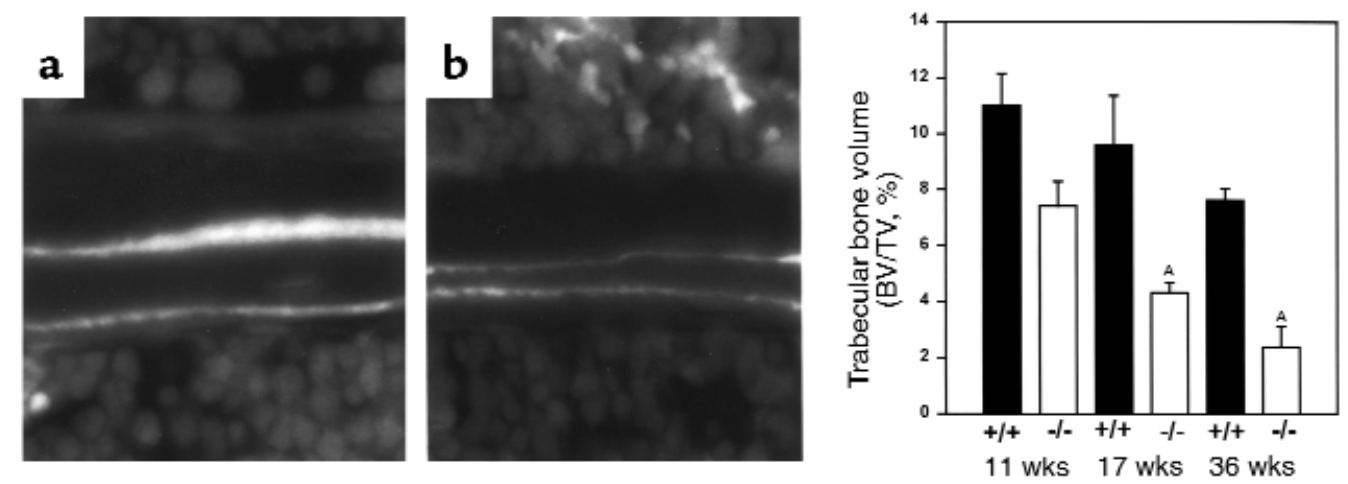

Figure 5

Trabecular bone-formation rate in tibiae of control (+/+) and osteonectin-null (-/-) mice. In vivo dual calcein labeling allows an estimate of boneformation rate, which considers the distance between 2 fluorescent labels. Representative data from 11-week-old control (a) and osteonectinnull (b) mice are shown. Bars show mean $\pm \operatorname{SEM}(n \geq 4)$. ${ }^{A} P<0.01$ between control and mutant mice, as determined by 2 -way ANOVA.

probe hybridized with transcripts of approximately 4 $\mathrm{kb}$ and $2.4 \mathrm{~kb}$. Interestingly, the smaller transcript appears to be absent in bone from osteonectin-null mice (Figure 6).

Overall, the osteonectin-null mice have decreased bone turnover as a result of decreased basic multicellular units (BMUs), the functional unit of osteoblasts and osteoclasts responsible for bone remodeling. The decreased bone-formation rate in the osteonectin-null mice and their decreased trabecular bone volume compared with control animals indicate that the mutant mice have a negative bone balance, leading to lowturnover osteopenia that becomes severe with age.

\section{Discussion}

Our data document, we believe for the first time, a role for osteonectin in bone, a tissue enriched in this glycoprotein. We find that osteonectin is critical in the support of bone remodeling and maintenance of bone mass. Osteonectinnull mice have decreased numbers of osteoblasts and osteoclasts, indicating decreased bone turnover as a result of decreased BMUs of remodeling. Compared with control animals, the decrease in bone formation exceeded the decrease in osteoclast number, causing a progressive decline in trabecular bone volume in the osteonectin-null mice and leading to low-turnover osteopenia.
The decreased trabecular bone volume in the osteonectin-null mice demonstrates the detrimental effect of the mutation on bone microarchitecture. Whereas the osteonectin-null mutation did not significantly affect cortical bone thickness, both cortical and trabecular bone-formation rate were decreased in the mutant mice. This suggests that matrix degradation in the cortical bone of mutant mice was reduced to a greater extent than in trabecular bone, or that, in general, osteoclastic activity in trabecular bone is greater than that in cortical bone since trabecular bone is most susceptible to loss of mass in states of increased resorption $(1,2)$. The slightly different effect of the osteonectin-null mutation on cortical and trabecular bone is not unexpected because they are biochemically distinct and may be subject to distinct regulatory mechanisms. Furthermore, normal human trabecular bone has 20- to 40-fold more osteonectin than cortical bone, which may make trabecular bone more sensitive to the osteonectin-null mutation (45).

Although serum osteocalcin levels were lower in aged osteonectin-null mice, for the most part there were no significant differences between control and mutant mice in the biochemical parameters tested. This may be due to the lower sensitivity of biochemical parameters compared with histomorphometry and to the limited

Table 2

Biochemical parameters of bone turnover in control and osteonectin-null mice

\begin{tabular}{lcccc}
\hline Parameter & Mouse type & 11 weeks & 17 weeks & 36 weeks \\
Serum osteocalcin & Control & $28.4 \pm 1.7$ & $18.0 \pm 2.0$ & $2.9 \pm 1.0$ \\
$(\mathrm{ng} / \mathrm{mL})$ & Osteonectin-null & $23.6 \pm 1.0$ & $19.2 \pm 2.7$ & Undetectable \\
Total urinary & Control & ND & $32.4 \pm 2.2$ & $33.6 \pm 4.1$ \\
deoxypyridinoline & Osteonectin-null & ND & $37.9 \pm 3.8$ & $36.1 \pm 2.1$
\end{tabular}

$(\mathrm{nM} / \mathrm{mM})$

Biochemical parameters of bone remodeling were determined in 11-, 17-, and 36-week-old control and osteonectin-null mice. Data shown are mean \pm SEM $(n \geq 4)$. Serum osteocalcin, a marker of bone formation, was determined by specific radioimmunoassay and total urinary deoxypyridinoline, a marker of bone degradation, was measured by ELISA and normalized for urinary creatinine levels. There were no significant differences between control and mutant mice, as determined by 2-way ANOVA. The limit of detection for the serum osteocalcin assay is $1.5 \mathrm{ng} / \mathrm{mL}$. ND, not done. 
effect of the mutation on cortical bone, which may have reduced detectable differences between control and mutant mice. Similar to the serum studies, the levels of osteocalcin mRNA in homogenates of whole bones were not different between control and osteonectin-null mice. Regarding the data on urinary collagen cross-links, it has been documented that urinary deoxypyridinoline is poorly correlated with bone resorption as assessed by histomorphometry (46). Indeed, the correlation between biochemical parameters of bone remodeling and bone mineral density is greater in high-turnover than in low-turnover states, such as that seen in the osteonectin-null mice (47). Furthermore, for the most part, data on the utility of biochemical parameters as markers of bone remodeling is derived from human studies, and their value in animal models is less well documented.

Whereas changes in cortical bone thickness were not observed, a 3-point bending test revealed that osteonectin-null mice had bone of lesser stiffness than control mice. The assay showed that femora from control mice gained strength from 11 to 17 weeks of age, then lost strength between 17 and 36 weeks, whereas the strength of femora from osteonectin-null mice did not change from 11 to 36 weeks of age. A significant difference in the bone strength of control and mutant mice was found at 17 weeks of age, a time of peak bone mass in the mouse (48). Whereas the 3-point bending test primarily measures the biomechanical properties of cortical tissue, it does not exclude the contribution of trabecular bone to the structural integrity of the bone in its totality. Therefore, the results of the 3-point bending test are not surprising, despite the lack of difference in cortical thickness. The data also suggest that whereas the osteonectin-null mutation did not affect the thickness of the cortical bone, its quality is not the same as that found in control mice. This idea is supported by the fact that preliminary data obtained using Fourier transform infrared microscopic analysis indicate that the cortical bone in the osteonectin-null mice has a higher mineral-to-matrix ratio, suggesting decreased matrix content (49).

We found that bones from osteonectin-null mice consistently yielded less total RNA than bones from control animals, an observation that correlates with the general decrease in bone cell number found in the mutant animals (A. Delany, unpublished data). However, Northern blots containing equivalent amounts of RNA showed that osteonectin-null and control mice expressed similar transcript levels for the major bone matrix components $\alpha 1$ (I) collagen, fibronectin, and bone sialoprotein. These data suggest that the matrix deposition function of the mutant osteoblasts may not be seriously affected. Whereas misexpression of osteonectin in Xenopus embryos and nematodes results in developmental defects, the skeletal development of the osteonectin-null mice appears to be normal $(6,16,17)$. Northern blot analysis showed that control and osteonectin-null mice had similar tran- script levels for the calcium-binding extracellular matrix proteins osteocalcin and osteopontin, suggesting that they may not be involved in compensating for the osteonectin-null mutation. Interestingly, SC1, which has 70\% similarity to osteonectin, is coexpressed with osteonectin in embryonic bone, suggesting that osteonectin and SC1 may have redundant functions in skeletogenesis (50). Given the progressive decline in trabecular bone volume in adults, osteonectin may be more important in remodeling adult bone than in development and growth.

Previous studies suggested that osteonectin can stimulate angiogenesis. Several mouse models have demonstrated that disruption of angiogenesis in bone results in perturbation of the growth plate; however, the growth plate is normal in osteonectin-null mice $(42,43)$. Bone from control mice displayed 2 VEGF transcripts. The smaller transcript could be due to alternative splicing, or it may represent cross hybridization of the probe with another member of the VEGF family $(51,52)$. The smaller transcript appears to be absent in bones from osteonectin-null mice, although the significance of this is unclear. Whereas the mutant mice may have a neovascularization defect, it is possible that another global process important in bone formation is affected by the osteonectin-null mutation.

The phenotype of osteonectin-null mice differs substantially from that of mice carrying null mutations in other noncollagenous extracellular matrix genes. Osteocalcin-deficient mice display increased bone formation, whereas biglycan-deficient mice have reduced bone mass owing to reduced bone for-

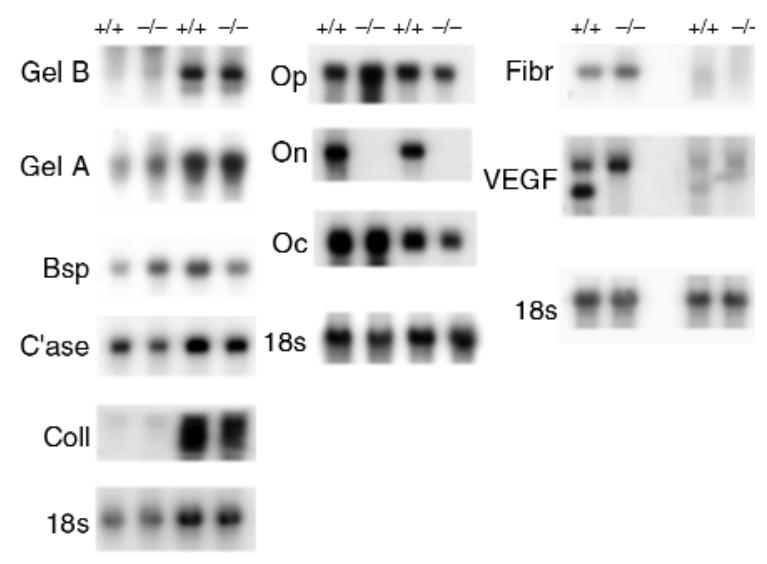

\section{Figure 6}

Analysis of mRNA in bone from control $(+/+)$ and osteonectin null $(-/-)$ mice. RNA from bone of 17-week-old mice was subjected to Northern blot analysis. Replicate Northern blots were probed with ${ }^{32}$ P-labeled cDNA for bovine osteonectin (On), mouse bone sialoprotein (Bsp), mouse osteopontin (Op), rat fibronectin (Fibr), rat $\alpha 1(\mathrm{I})$ collagen (Coll), rat osteocalcin (Oc), mouse gelatinase B (GelB), human gelatinase A (Gel-A), rat collagenase-3 (C'ase), VEGF. Mouse 18S rRNA cDNA (18S) was used as a control for RNA loading. Appropriate exposures were analyzed using densitometry. 
mation, with no change in osteoclast surface and very modest decreases in osteoblast surface $(53,54)$. Osteonectin-deficient mice have a dramatic decrease in osteoclast and osteoblast surface with decreased bone formation leading to development of a lowturnover osteoporosis-like phenotype affecting trabecular bone. Senile osteoporosis in aged humans is another example of low-turnover osteopenia, resulting in decreased cortical as well as trabecular bone. In this disease, there is decreased bone turnover with the decrease in bone formation exceeding the decrease in bone resorption. It is proposed that one component of senile osteoporosis is impaired osteoblastic function. In contrast, high-turnover osteopenia, like that seen in the period immediately following estrogen depletion or in hyperparathyroidism, results from increased bone turnover, with bone resorption outpacing bone formation. In high-turnover osteopenia, trabecular bone is primarily affected (55).

In summary, we find that osteonectin-null mice develop a low-turnover osteopenia, resulting in trabecular bone with compromised mass, microarchitecture, and biomechanical properties. Current data suggest that osteopenia in osteonectin-null mice primarily is due to a progressive decrease in bone cell number. It is possible that decreased expression of osteonectin can contribute to bone fragility associated with some osteopenic states, such as osteogenesis imperfecta, and it is possible that osteonectin gene mutations or polymorphisms may play a role in inherited susceptibility to osteoporosis (13-15).

\section{Acknowledgments}

We thank G. Opdenakker for the gelatinase B cDNA; C. Quinn for the collagenase-3 cDNA; M. Young for the osteonectin, bone sialoprotein, and osteopontin cDNAs; J. Lian for the osteocalcin cDNA; D. Rowe for the $\alpha 1(\mathrm{I})$ procollagen $\mathrm{cDNA}$; and R. Hynes for the fibronectin cDNA. We thank Adele Boskey for data on the mineral properties of osteonectin-null mice. We thank Cathy Boucher, Eric Gelke, and Meagen Marcy for technical assistance, and Tim Holzmann for performing biomechanical testing. This work was supported by grants from the National Institutes of Health (AR-44877 to A.M. Delany, AR-21707 to E. Canalis, and DE-04724 to R. Baron), the Wistar Institute (to C.C. Howe), and the AO ASIF Research Foundation (AO 2000-A26, to M. Amling).

1. Margolis, R.N., Canalis, E., and Partridge, N.C. 1996. Anabolic hormones in bone: basic research and therapeutic potential. J. Clin. Endocrinol. Metab. 81:872-877.

2. Baron, R.E. 1996. Anatomy and ultrastructure of bone. In Primer on the metabolic bone diseases and disorders of mineral metabolism. M.J. Favus, editor. Lippincott-Raven Publishers. New York, NY. 3-10.

3. Keen, R.W., and Kelly, P.J. 1997. Genetic factors in osteoporosis. What are the implications for prevention and treatment? Drugs Aging. 11:333-337.

4. Corral, D., et al. 1998. Dissociation between bone resorption and bone formation in osteopenic transgenic mice. Proc. Natl. Acd. Sci., USA. 95:13835-13840

5. Young, M.F., Kerr, J.M., Ibaraki, K., Heegaard, A.M., and Gehron Robey, P. 1992. Structure, expression, and regulation of the major noncollage- nous matrix proteins of bone. Clin. Orthop. 281:275-294.

6. Lane, T.F., and Sage, E.H. 1994. The biology of SPARC, a protein that modulated cell-matrix interactions. FASEB J. 8:163-173.

7. Shankavaram, U.T., DeWitt, D.L., Funk, S.E., Sage, E.H., and Wahl, L.M. 1997. Regulation of human monocyte matrix metalloproteinases by SPARC. J. Cell. Physiol. 173:327-334.

8. Tremble, P.M., Lane, T.F., Sage, E.H., and Werb, Z. 1993. SPARC, a secreted protein associated with morphogenesis and tissue remodeling, induces expression of metalloproteinases in fibroblasts through a novel extracellular matrix-dependent pathway. J. Cell Biol. 121:1433-1444.

9. Wrana, J.L., et al. 1988. Differential effects of transforming growth factor-b on the synthesis of extracellular matrix proteins by normal fetal rat calvarial bone cell populations. J. Cell Biol. 106:915-924.

10. Nakamura, S., et al. 1996. Enhancement of SPARC (osteonectin) synthesis in arthritic cartilage. Increased levels in synovial fluids from patients with rheumatoid arthritis and regulation by growth factors and cytokines in chondrocyte cultures. Arthritis Rheum. 39:539-551.

11. Delany, A.M., and Canalis, E. 1998. Basic fibroblast growth factor destabilizes osteonectin mRNA in osteoblasts. Am. J. Physiol. 274:C734-C740.

12. Ng, K.W., Manji, S.S., Young, M.F., and Findlay, D.M. 1989. Opposing influences of glucocorticoid and retinoic acid on transcriptional control in preosteoblasts. Mol. Endocrinol. 3:2079-2085.

13. Muriel, M.P., et al. 1991. Morphological and biochemical studies of a mouse mutant (fro/fro) with bone fragility. Bone. 12:241-248.

14. Fedarko, N.S., Gehron Robey, P., and Vetter, U.K. 1995. Extracellular matrix stoichiometry in osteoblasts from patients with osteogenesis imperfecta. J. Bone Miner. Res. 10:1122-1129.

15. Fisher, L.W., Drum, M.A., Gehron Robey, P., Conn, K.M., and Termine, J.D. 1987. Osteonectin content in human osteogenesis imperfecta bone shows a range similar to that of two bovine models of OI. Calcif. Tissue Int. 40:260-264.

16. Norose, K., et al. 1998. SPARC deficiency leads to early onset cataractogenesis. Invest. Ophthalmol. Vis. Sci. 39:2674-2680.

17. Gilmour, D.T., et al. 1998. Mice deficient for the secreted glycoprotein SPARC/osteonectin/BM40 develop normally but show severe age-onset cataract formation and disruption of the lens. EMBO J. 17:1860-1870.

18. Amling, M., et al. 1997. Bcl-2 lies downstream of parathyroid hormonerelated peptide in a signaling pathway that regulates chondrocyte maturation during skeletal development. J. Cell Biol. 136:205-213.

19. Parfitt, A.M., et al 1987. Bone histomorphometry: standardization of nomenclature, symbols and units. J. Bone Miner. Res. 6:595-610.

20. Baron, R., Tross, R., and Vignery, A. 1984. Evidence of sequential remodeling in rat trabecular bone: morphology, dynamic histomorphometry, and changes during skeletal maturation. Anat. Rec. 208:137-145.

21. Amling, M., et al. 1999. Rescue of the skeletal phenotype of vitamin D receptor ablated mice in the setting of normal mineral ion homeostasis: formal histomorphometric and biomechanical analysis. Endocrinology. 140:4982-4987.

22. Chomczynski, P., and Sacchi, N. 1987. Single-step method of RNA isolation by acid guanidinium thiocyanate-phenol-chloroform extraction. Anal. Biochem. 162:156-159.

23. Quinn, C.O., et al. 1990. Rat collagenase: cloning, amino acid sequence comparison, and parathyroid hormone regulation in osteoblastic cells. J. Biol. Chem. 265:22342-22347.

24. Bolander, M.E., Young, M.F., Fisher, L.W., Yamada, Y., and Termine, J.D. 1988. Osteonectin cDNA sequence reveals potential binding regions for calcium and hydroxyapatite and shows homologies with both a basement membrane protein (SPARC) and a serine proteinase inhibitor (ovomucoid). Proc. Natl. Acad. Sci. USA. 85:2919-2923.

25. Young, M.F., Ibaraki, K., Kerr, J.M., Lyu, M.S., and Kozak, C.A. 1994. Murine bone sialoprotein (BSP): cDNA cloning, mRNA expression, and genetic mapping. Mamm. Genome. 5:108-111.

26. Schwarzbauer, J.E., Tamkun, J.W., Lemischka, I.R., and Hynes, R.O. 1983. Three different fibronectin $\mathrm{mRNAs}$ arise by alternative splicing within the coding region. Cell. 35:421-431.

27. Lian, J., et al. 1989. Structure of the rat osteocalcin gene and regulation of vitamin D-dependent expression. Proc. Natl. Acad. Sci. USA. 86:1143-1147.

28. Masure, S., Nys, G., Fiten, P., Van Damme, J., and Opdenakker, G. 1993. Mouse gelatinase B. cDNA cloning, regulation of expression and glycosylation in WEHI-3 macrophages and gene organization. Eur. J. Biochem. 218:129-141

29. Levy, A.T., et al. 1991. Increased expression of the Mr 72,000 type IV collagenase in human colonic adenocarcinoma. Cancer Res. 51:439-444.

30. Genovese, C., Rowe, D., and Kream, B. 1984. Construction of DNA sequences complementary to rat $\mathrm{a}_{1}$ and $\mathrm{a}_{2}$ collagen mRNA and their use in studying the regulation of type I collagen synthesis by 1,25 -dihydroxyvitamin D. Biochemistry. 23:6210-6216.

31. Tso, J.Y., Sun, X.H., Kau, T.-H., Reece, K.S., and Wu, R. 1985. Isolation and characterization of rat and human glyceraldehyde-3-phosphate dehydrogenase cDNAs: genomic complexity and molecular evaluation of the gene. Nucleic Acids Res. 13:2485-2502.

32. Lennon, G., Auffray, C., Polymeropoulos, M., and Soares, M.B. 1996. The 
I.M.A.G.E. consortium: an integrated molecular analysis of genomes and their expression. Genomics. 33:151-152.

33. Gundberg, C.M., Hauschka, P.V., Lian, J.B., and Gallop, P.M. 1984 Osteocalcin: isolation, characterization, and detection. Methods Enzymol. 107:516-544.

34. Kimble, R.B., et al. 1994. Interleukin-1 receptor antagonist decreases bone loss and bone resorption in ovariectomized rats. J. Clin. Invest. 93:1959-1967.

35. Recker, R.R. 1996. Bone remodeling abnormalities in osteoporosis. In Osteoporosis. R. Marcus, D. Feldman, and J. Kelsey, editors. Academic Press. San Diego, CA. 703-713.

36. Khosla, S., and Kleerekoper, M. 1999. Biochemical markers of bone turnover. In Primer on the metabolic bone diseases and disorders of mineral metabolism. M.H.J. Flavus, editor. Lippincott Williams and Wilkins. Philadelphia, PA. 128-134

37. Rifas, L., Fausto, A., Scott, M.J., Avioli, L.V., and Welgus, H.G. 1994. Expression of metalloproteinases and tissue inhibitors of metalloproteinases in human osteoblast-like cells: differentiation is associated with repression of metalloproteinase synthesis. Endocrinology. 134:213-221.

38. Lorenzo, J.A., Pilbeam, C.C., Kalinowski, J.F., and Hibbs, M.S. 1992. Production of both $92-$ and $72-\mathrm{kDa}$ gelatinases by bone cells. Matrix. 12:282-290.

39. Delany, A.M., and Canalis, E. 1998. Dual regulation of stromelysin-3 by fibroblast growth factor-2 in murine osteoblasts. J. Biol. Chem. 273:16595-16600.

40. Tezuka, K., et al. 1994. Identification of matrix metalloproteinase 9 in rabbit osteoclasts. J. Biol. Chem. 269:15006-15009.

41. Sato, T., et al. 1997. Identification of the membrane-type matrix metalloproteinase MT1-MMP in osteoclasts. J. Cell Sci. 110:589-596.

42. Vu, T.H., et al. 1998. MMP-9/gelatinase B is a key regulator of growth plate angiogenesis and apoptosis of hypertrophic chondrocytes. Cell. 93:411-422.

43. Gerber, H.P., et al. 1999. VEGF couples hypertrophic cartilage remodeling, ossification and angiogenesis during endochondral bone formation. Nat. Med. 5:623-628.
44. Wang, D.S., Miura, M., Demura, H., and Sato, K. 1997. Anabolic effects of 1,25-dihydroxyvitamin D3 on osteoblasts are enhanced by vascular endothelial growth factor produced by osteoblasts and by growth factors produced by endothelial cells. Endocrinology. 138:2953-2962.

45. Ninomiya, J.T., et al. 1990. Heterogeneity of human bone. J. Bone Miner. Res. 5:933-938.

46. Delmas, P.D. 1990. Biochemical markers of bone turnover for the clinical assessment of metabolic disease. Endocrinol. Metab. Clin. North Am. 19:1-18.

47. Jodar Gimeno, E., et al. 1997. Identification of metabolic bone disease in patients with endogenous hyperthyroidism: role of biological markers of bone turnover. Calcif. Tissue Int. 61:370-376.

48. Beamer, W.G., et al. 1996. Genetic variability in adult bone density among inbred strains of mice. Bone. 18:397-403.

49. Boskey, A., Spevak, L., Amling, M., Canalis, E., and Delany, A. 2000. Mineral analysis of osteonectin-deficient mouse bones confirms altered remodeling activity. Transactions of the Orthopedic Research Society. 26:135. http://www.ors.org

50. Soderling, J.A., Reed, M.J., Corsa, A., and Sage, E.H. 1997. Cloning and expression of murine SC1, a gene product homologous to SPARC. J. Histochem. Cytochem. 45:823-835.

51. Shima, D.T., et al. 1996. The mouse gene for vascular endothelial growth factor: genomic structure, definition of the transcriptional unit, and characterization of transcriptional and post-transcriptional regulatory sequences. J. Biol. Chem. 271:3877-3883.

52. Neufeld, G., Cohen, T., Gengrinovitch, S., and Poltorak, Z. 1999. Vascular endothelial growth factor (VEGF) and its receptors. FASEBJ. 13:9-22.

53. Ducy, P., et al. 1996. Increased bone formation in osteocalcin-deficient mice. Nature. 382:448-452.

54. Xu, T., et al. 1998. Targeted disruption of the biglycan gene leads to an osteoporosis-like phenotype in mice. Nat. Genet. 20:78-82.

55. Kassem, M., Melton, L.J., III, and Riggs, B.L. 1996. The type I/type II model for involutional osteoporosis. In Osteoporosis. R. Marcus, D. Feldman, and J. Kelsey, editors. Academic Press. San Diego, CA. 703-713. 